NBER WORKING PAPER SERIES

\title{
SIBLING AND INTERGENERATIONAL CORRELATIONS IN WELFARE PROGRAM PARTICIPATION
}

\author{
Gary Solon \\ Mary Corcoran \\ Roger Gordon \\ Deborah Laren
}

Working Paper No. 2334

\author{
NATIONAL BUREAU OF ECONOMIC RESEARCH \\ 1050 Massachusetts Avenue \\ Cambridge, MA 02138 \\ August 1987
}

This research was supported by a grant from the Ford Foundation to the Institute of Public Policy Studies at The University of Michigan. The authors thank John Bound, Charles Brown, and Greg Duncan for their comments. The research reported here is part of the NBER's research program in Labor Studies. Any opinions expressed are those of the authors and not those of the National Bureau of Economic Research. 
NBER Working Paper \#2334

August 1987

Sibling and Intergenerational Correlations in Welfare Program Participation

\section{ABSTRACT}

Many previous studies have used sibling correlations to measure the effect of family background on earnings, income, and occupational status. This paper uses data on a sample of sisters to explore the importance of family background as a determinant of welfare program participation. The results show a strikingly high degree of sibling resemblance in welfare receipt. For example, a woman's estimated probability of having participated in welfare programs is .20 if her sister has not participated, but is .66 if her sister has participated.

Gary Solon

Department of Economics

The University of Michigan

Ann Arbor, MI 48109-1220

(313) 763-1306

Roger Gordon

Department of Economics

The University of Michigan

Ann Arbor, MI 48109-1220

(313) 764-6769
Mary Corcoran

Department of Political Science

The University of Michigan

Ann Arbor, MI 48109-1220

(313) 764-9517

Deborah Laren

Institute for Social Research The University of Michigan

Ann Arbor, MI 48109-2321

(313) 936-0308 


\section{Sibling and Intergenerational Correlations in Welfare Program Participation}

Both social scientists and policymakers have expressed concern about the influence of family background on welfare program participation. According to Rein and Rainwater (1978), for example, "One common view of the welfare 'crises,' and spiraling welfare costs, is that the principal cause is the growth of a welfare class, which passes on a legacy of dependency to its children." Such a view seems to underlie President Reagan's frequent references to "the welfare culture," "the breakdown of the family," and "the spider's web of dependency."1

Many previous studies have examined the influence of family background on earnings, income, and other measures of economic status besides welfare program participation. Some of these studies have attempted to measure the importance of family background by estimating sibling correlations. ${ }^{2}$ The idea is that, if family background matters very much, siblings will show a strong resemblance in economic status; if it matters hardly at all, they will show little more resemblance than would randomly selected unrelated individuals. This paper similarly adopts the device of using measured sibling resemblance to explore the importance of family background as a determinant of welfare

${ }^{1}$ See, for example, “Transcript of President's Speech to Congress on State of Union" (1985).

${ }^{2}$ This literature is discussed in Corcoran and Jencks (1979) and Solon, Corcoran, Gordon, and Laren (1987). 
program participation. The results display a startlingly high degree of sibling resemblance in welfare receipt.

In the next section, we describe our statistical model and estimation strategy. Then we present our results on sibling resemblance as well as related results on the intergenerational correlation in welfare receipt. Finally, we summarize and discuss our findings.

\section{Statistical Model and Estimation Strategy}

Our study is designed to estimate three parameters for a population of sister pairs: $p=$ the unconditional probability that a randomly selected woman has participated in welfare programs, $p_{0}=$ the conditional probability that she has participated given that her sister has not participated, and $p_{1}=$ the conditional probability that she has participated given that her sister has participated. These parameters are related by the identity $\mathrm{p} \equiv \mathrm{p}_{0} /\left(1+\mathrm{p}_{0}-\mathrm{p}_{1}\right)$. If family background has little effect on welfare program participation, sisters should show little resemblance in participation status. In that case, $\mathrm{p}_{0}$ and $\mathrm{p}_{1}$ should be close together. On the other hand, if family background is very influential, sisters should show a large resemblance, and $p_{1}$ should be much greater than $\mathrm{p}_{0}$. In fact, $\mathrm{p}_{1}-\mathrm{p}_{0}$ can be shown to be exactly equivalent to the sister correlation in welfare program participation.

One can divide a sample of $\mathrm{N}$ sister pairs into three groups: the $\mathrm{N}_{00}$ pairs in which neither sister participated, the $\mathrm{N}_{01}+\mathrm{N}_{10}$ pairs in which only one sister participated, and the $\mathrm{N}_{11}$ pairs in which both sisters participated. The likelihood function for a random sample is then

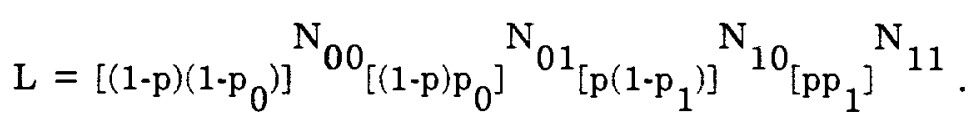

Substituting $\mathrm{p}$ out with the identity above, rearranging terms, and taking logarithms produce the log likelihood function 


$$
\begin{aligned}
\ln L=-N & \ln \left(1+\mathrm{p}_{0}-\mathrm{p}_{1}\right)+\left(\mathrm{N}-\mathrm{N}_{00}\right) \ln \mathrm{p}_{0} \\
& +\mathrm{N}_{00} \ln \left(1-\mathrm{p}_{0}\right)+\left(\mathrm{N}-\mathrm{N}_{11}\right) \ln \left(1-\mathrm{p}_{1}\right)
\end{aligned}
$$

This log likelihood function is maximized by the estimators

$$
\begin{aligned}
& \hat{\mathrm{p}}_{0}=\left(\mathrm{N}_{01}+\mathrm{N}_{10}\right) /\left(2 \mathrm{~N}_{00}+\mathrm{N}_{01}+\mathrm{N}_{10}\right) \\
& \hat{\mathrm{p}}_{1}=2 \mathrm{~N}_{11} /\left(\mathrm{N}_{01}+\mathrm{N}_{10}+2 \mathrm{~N}_{11}\right) .
\end{aligned}
$$

Once derived and contemplated, these estimators become obvious. The parameter $\mathrm{p}_{0}$, the probability of having participated if one's sister has not, is estimated by counting up the number of women in the sample whose sisters did not participate and then calculating the fraction of that group that did participate. Similarly, $p_{1}$, the probability of having participated if one's sister has, is estimated by the participation rate among the sampled women whose sisters did participate.

We have applied a variant of this estimation approach to data from the Panel Study of Income Dynamics (PSID). Adult sister pairs can be obtained from the PSID because the survey follows children from the original PSID families after they leave home. Our sample consists of pairs of sisters that became heads of their own households or wives of heads and that were between the ages of 27 and 32 at the time of the 1983 interview (and thus between 12 and 17 at the outset of the PSID in 1968). Women that were over the age of 17 in 1968 and entered the PSID because they were still living in their parents' households are excluded to avoid overrepresenting women that left home at late ages. The sample is restricted to women at least 27 in 1983 to ensure that the women have had several years' opportunity to receive welfare. In families with more than two sisters in the relevant age range, we use the two oldest. The resulting sample contains 137 pairs of sisters. 
Our main measure of welfare program participation is simply whether the woman ever reported welfare receipt between the time of leaving home and age $27 .^{3} \mathrm{We}$ will focus on results based on a welfare definition that includes AFDC, general assistance, food stamps, and SSI, but we also will mention results arising from a more restrictive definition.

We would have applied the above-described estimation approach without modification, except for one problem - the PSID systematically oversampled the lowincome population. As a result, sample proportions inconsistently estimate the corresponding population proportions. An obvious example is that the sample rates of welfare program participation will tend to be higher than the population rates. To correct for this inconsistency, we base the estimators $\hat{\mathrm{p}}_{0}$ and $\hat{\mathrm{p}}_{1}$ not on simple frequency counts as in equations (1), but instead on counts of observations weighted by the inverse of their probabilities of selection into the sample. ${ }^{4}$

This procedure solves the consistency problem, but complicates the estimation of standard errors for our parameter estimators. Since the estimators are no longer derived as maximum likelihood estimators, the conventional standard error estimators for maximum likelihood estimators do not apply. Instead, we have used a nonparametric "balanced half-sample replication" procedure. This approach - described in detail in Kish and Frankel (1970), McCarthy (1969), and Wolter (1985) - repeatedly applies the parameter estimators to a succession of strategically chosen half-samples. Each estimator's observed variance across the half-sample replications is then used to infer an

${ }^{3}$ More precisely, the measure is whether her family (that is, the one in which she was the head or wife) reported welfare receipt during the indicated time interval. We consider welfare receipt reported only through age 27 (even for sample women that can be observed until later ages) in an effort to standardize the measurement of this variable.

${ }^{4}$ This technique has been suggested in related contexts by Hausman and Wise (1981) and Manski and Lerman (1977). For each sister pair, we use the sum of the sisters' values of the weight described on page 459 of Survey Research Center (1985). Pages 6-19 of Survey Research Center (1979) give a detailed explanation of the construction of the weight. 
estimate of the variance of that estimator as applied to the full sample. Our implementation of this procedure is described more fully in the Appendix.

\section{Results}

The initial results from our analysis of the PSID sister pairs are shown in the first row of Table 1. The unconditional welfare program participation rate $(\hat{p})$ is estimated at .371. This figure may seem high at first, but is not dramatically larger than previous estimates of population proportions ever receiving welfare over some substantial time period. ${ }^{5}$ That it is somewhat higher should not be surprising given that our sister pairs necessarily represent a population of women from relatively large families. If we restrict our definition of welfare to AFDC and general assistance (excluding food stamps and SSI), p falls to $.245 .^{6}$

The conditional probability of participation given that one's sister did not participate $\left(\hat{\mathrm{p}}_{0}\right)$ is estimated at .199 . In comparison, the estimated conditional probability given that one's sister did participate $\left(\hat{\mathrm{p}}_{1}\right)$ is .662 , more than three times as large. As shown in the last column, the difference between $\hat{\mathrm{p}}_{1}$ and $\hat{\mathrm{p}}_{0}$ is well over four times its estimated standard error. Similar results appear if the welfare definition is restricted to AFDC and general assistance. Then $\hat{\mathrm{p}}_{0}=.163$ and $\hat{\mathrm{p}}_{1}=.498$, so that the latter remains over three times the former.

The second row shows how these results are affected if the measure of welfare program participation is whether the woman reported welfare receipt in at least three different calendar years. With this longer-term measure of welfare receipt, $\hat{p}=.216$, $\hat{\mathrm{p}}_{0}=.122$, and $\hat{\mathrm{p}}_{1}=.556$. By this measure, $\hat{\mathrm{p}}_{1}$ is well over four times $\hat{\mathrm{p}}_{0}$, and the difference between the two is almost four times its estimated standard error. The measured sister resemblance becomes sharper still if the welfare definition is restricted to

${ }^{5}$ See, for example, Duncan and Coe (1984).

${ }^{6}$ Almost the entire fall is accounted for by the exclusion of food stamps. Very few sample members received SSI. 
AFDC and general assistance. Then $\hat{\mathrm{p}}=.151, \hat{\mathrm{p}}_{0}=.070$, and $\hat{\mathrm{p}}_{1}=.605$. Long-term receipt of AFDC and general assistance is estimated to be over eight times more likely if one's sister is a long-term recipient than if she is not! The evidence of a large discrepancy between $\mathrm{p}_{0}$ and $\mathrm{p}_{1}$, no matter how they are estimated, implies that something about sisters' shared background heavily influences the probability of welfare program participation.

It occurred to us that race might be an especially important component of shared background. We therefore repeated our analysis separately for nonblacks and blacks (using the original measure of whether the woman ever reported welfare receipt). The results, shown in the third and fourth rows, indicate that blacks do indeed have about twice as high an unconditional participation rate. Even within race categories, however, the sister resemblance remains overwhelming. For nonblacks, $\hat{\mathrm{p}}_{0}=.183$ and $\hat{\mathrm{p}}_{1}=.607$; for blacks, $\hat{\mathrm{p}}_{0}=.355$ and $\hat{\mathrm{p}}_{1}=.801$. If the welfare definition is restricted to AFDC and general assistance, these figures become $\hat{\mathrm{p}}_{0}=.149$ and $\hat{\mathrm{p}}_{1}=.419$ for nonblacks and $\hat{\mathrm{p}}_{0}=$ .275 and $\hat{\mathrm{p}}_{1}=.677$ for blacks. Clearly, other shared background characteristics besides race are influential.

The strikingly large sister resemblance in welfare receipt made us curious also about the intergenerational correlation in welfare program participation. The last two rows show the results from an analysis broken down by whether the sisters' parents reported receiving welfare between 1968 and the time by which both sisters had left home. The intergenerational relationship is quite noticeable. The estimated unconditional participation rate is .503 for those whose parents received welfare as compared to .289 for those whose parents did not receive welfare. The difference is more than twice its estimated standard error (.093). Again, however, the sister resemblance within categories remains very large, indeed larger than the measured intergenerational resemblance. Among those whose parents received welfare, $\hat{\mathrm{p}}_{0}=.225$ and $\hat{\mathrm{p}}_{1}=.777$; among those whose parents did not receive welfare, $\hat{p}_{0}=.188$ and $\hat{p}_{1}=.537$. The corresponding 
estimates under the welfare definition restricted to AFDC and general assistance are $\hat{\mathrm{p}}_{0}=.156$ and $\hat{\mathrm{p}}_{1}=.682$ for those whose parents received welfare and $\hat{\mathrm{p}}_{0}=.165$ and $\hat{\mathrm{p}}_{1}=.412$ for those whose parents did not. Evidently, daughters' welfare program participation is influenced by other background characteristics beyond parental welfare receipt over the time period observed in the data.

\section{Summary and Discussion}

All the results in Table 1 display a startling resemblance among sisters in their welfare program participation. Given welfare eligibility rules in the U.S., this resemblance in welfare program participation must reflect a resemblance in both income status and propensity for motherhood without the father present. Indeed, in Solon, Corcoran, Gordon, and Laren (1987), we have estimated a .5 sister correlation in a measure of permanent income relative to needs. Also, using the same type of estimation procedure as in the present paper, we have found a sizable sister resemblance in the probability of having a child out of wedlock before the age of $20 .^{7}$ These findings suggest that the probabilities of experiencing poverty, single motherhood, and welfare receipt are greatly influenced by background characteristics shared by sisters.

A full understanding of these results (and identification of appropriate policy responses) would require an understanding of which background factors are crucial. Is it that parental income status tends to be passed on to the next generation? Is it that parents (or communities) instill sisters with common attitudes or values? To what extent is it simply that sisters tend to live in nearby locations with similar economic conditions and welfare program options? A few studies, including Rein and Rainwater (1978) and Hill and Ponza (1986), have made initial attempts to sort out the influences of different background characteristics on welfare program participation, but the combination of

\footnotetext{
${ }^{7}$ Preliminary results for this variable show $\hat{\mathrm{p}}_{0}=.077$ and $\hat{\mathrm{p}}_{1}=.240$.
} 
multicollinearity among the characteristics, measurement error, and omitted-variable problems makes the achievement of reliable answers a formidable task. 
Table 1

Estimated Probabilities of Welfare Program Participation (with Estimated Standard Errors)

\begin{tabular}{|lcccc|}
\hline & $\hat{\mathbf{p}}$ & $\hat{\mathbf{p}}_{\mathbf{0}}$ & $\hat{\mathbf{p}}_{\mathbf{1}}$ & $\hat{\mathbf{p}}_{\mathbf{1}} \hat{\mathbf{p}}_{\mathbf{0}}$ \\
\hline Full sample & .371 & .199 & .662 & .463 \\
& $(.032)$ & $(.040)$ & $(.071)$ & $(.105)$ \\
& .216 & .122 & .556 & .434 \\
$\begin{array}{l}\text { Full sample, } \\
\text { three-year partici- }\end{array}$ & $(.028)$ & $(.033)$ & $(.089)$ & $(.117)$ \\
pation measure & & & & \\
Nonblacks & .318 & .183 & .607 & .424 \\
& $(.040)$ & $(.044)$ & $(.110)$ & $(.145)$ \\
Blacks & .641 & .355 & .801 & .446 \\
& $(.067)$ & $(.150)$ & $(.079)$ & $(.205)$ \\
Parents received & .503 & .225 & .777 & .552 \\
welfare & $(.064)$ & $(.079)$ & $(.092)$ & $(.159)$ \\
$\begin{array}{l}\text { Parents did not } \\
\text { receive welfare }\end{array}$ & .289 & .188 & .537 & .349 \\
& $(.051)$ & $(.048)$ & $(.125)$ & $(.154)$ \\
\hline
\end{tabular}




\section{Appendix}

To facilitate half-sample replications, the Survey Research Center has characterized the PSID sample as consisting of two independent "primary selections" from each of 32 strata. The pair of selections in the $k^{\text {th }}$ stratum might be, say, the PSID samples from the Milwaukee and Minneapolis areas. The coding of these pairs is described on pages 89-90 and 310-11 of Survey Research Center (1985). A half-sample comprised of only one selection from each of the 32 strata more or less duplicates the complex survey design of the PSID, but at only about half the size.

We used the $32 \times 32$ Hadamard matrix on page 325 of Wolter (1985) to select a set of 32 "balanced" half-samples. For any parameter $\mu$, if $\hat{\mu}$ denotes the estimate from the full sample and $\hat{\mu}_{k}$ the estimate from the $k^{\text {th }}$ half-sample, we estimate the variance of $\hat{\mu}$ with

$$
\widehat{\operatorname{Var}}(\hat{\mu})=\sum_{k=1}^{32}\left(\hat{\mu}_{k}-\hat{\mu}\right)^{2} / 32 .
$$

Why is this a sensible estimator of $\operatorname{Var}(\hat{\mu})$ ? Let $\hat{\mu}_{\mathrm{k}^{\prime}}$ denote the estimate of $\mu$ from the complement of the $\mathrm{k}^{\text {th }}$ half-sample, and suppose $\hat{\mu}=\left(\hat{\mu}_{\mathrm{k}}+\hat{\mu}_{\mathrm{k}^{\prime}}\right) / 2$, as is exactly true if $\hat{\mu}$ is a linear estimator and is likely to be approximately true otherwise. Then, for any arbitrary half-sample $\mathrm{k}$,

$$
\begin{aligned}
& \mathrm{E}\left(\hat{\mu}_{\mathrm{k}}-\hat{\mu}\right)^{2}=\mathrm{E}\left[\hat{\mu}_{\mathrm{k}}-\left(\hat{\mu}_{\mathrm{k}}+\hat{\mu}_{\mathrm{k}^{\prime}}\right) / 2\right]^{2} \\
& =\mathrm{E}\left[\left(\hat{\mu}_{\mathrm{k}}-\hat{\mu}_{\mathrm{k}^{\prime}}\right) / 2\right]^{2} \\
& =\mathrm{E}\left(\hat{\mu}_{\mathbf{k}}-\hat{\mu}_{\mathbf{k}}\right)^{2} / 4 \\
& =\mathrm{E}\left[\left(\hat{\mu}_{\mathbf{k}}-\mu\right)-\left(\hat{\mu}_{\mathbf{k}^{\prime}}-\mu\right)\right]^{2} / 4 \\
& =2 \operatorname{Var}\left(\hat{\mu}_{\mathrm{k}}\right) / 4 \\
& =\operatorname{Var}\left(\hat{\mu}_{\mathbf{k}}\right) / 2
\end{aligned}
$$




$$
=\operatorname{Var}(\hat{\mu}) .
$$

Thus, for any particular half-sample $\mathbf{k}$, the squared deviation of $\hat{\mu}_{\mathbf{k}}$ from $\hat{\mu}$ is an approximately unbiased estimator of $\operatorname{Var}(\hat{\mu})$. The point of taking 32 different halfsamples and averaging the squared deviations of the $\hat{\mu}_{\mathrm{k}}$ from $\hat{\mu}$ is to improve the precision of the variance estimator. The optimal method of choosing "balanced" half-sample replications is discussed in detail in McCarthy (1969) and Wolter (1985). 


\section{References}

Corcoran, Mary, and Christopher Jencks. "The Effects of Family Background." Chapter 3 in Christopher Jencks et al., Who Gets Ahead? New York: Basic Books, 1979.

Duncan, Greg J., and Richard D. Coe. "The Dynamics of Welfare Use." Chapter 3 in Greg J. Duncan, Years of Poverty, Years of Plenty. Ann Arbor: Institute for Social Research, The University of Michigan, 1984.

Hausman, Jerry A., and David A. Wise. "Stratification on Endogenous Variables and Estimation: The Gary Income Maintenance Experiment." Structural Analysis of Discrete Data with Econometric Applications, ed. by Charles F. Manski and Daniel McFadden. Cambridge: MIT Press, 1981.

Hill, Martha S., and Michael Ponza. "Does Welfare Dependency Beget Dependency?" Unpublished, 1986.

Kish, Leslie, and Martin R. Frankel. "Balanced Repeated Replications for Standard Errors." Journal of the American Statistical Association 65 (September 1970): 107194.

Manski, Charles F., and Steven R. Lerman. "The Estimation of Choice Probabilities from Choice Based Samples." Econometrica 45 (November 1977): 1977-88.

McCarthy, Philip J. "Pseudo-Replication: Half Samples." Review of the International Statistical Institute 37 (1969): 239-64.

Rein, Martin, and Lee Rainwater. "Patterns of Welfare Use." Social Service Review 52 (December 1978): 511-34.

Solon, Gary, Mary Corcoran, Roger Gordon, and Deborah Laren. "The Effect of Family Background on Economic Status: A Longitudinal Analysis of Sibling Correlations." Working Paper No. 2282, National Bureau of Economic Research, June 1987.

Survey Research Center. A Panel Study of Income Dynamics: Procedures and Tape Codes, 1978 Interviewing Year - Wave XI, A Supplement. Ann Arbor: Institute for Social Research, The University of Michigan, 1979.

Survey Research Center. A Panel Study of Income Dynamics: Procedures and Tape Codes, 1983 Interviewing Year - Wave XVI, A Supplement. Ann Arbor: Institute for Social Research, The University of Michigan, 1985.

"Transcript of President's Speech to Congress on State of Union." New York Times, February 5, 1986, page 10.

Wolter, Kirk. Introduction to Variance Estimation. New York: Springer-Verlag, 1985. 